\title{
Elevated nocturnal NEFA are an early signal for hyperinsulinaemic compensation during diet-induced insulin resistance in dogs
}

\author{
Josiane L. Broussard $^{1}$ - Cathryn M. Kolka ${ }^{1}$ Ana V. B. Castro ${ }^{1}$ - Isaac Asare Bediako ${ }^{1}$. \\ Rebecca L. Paszkiewicz ${ }^{1} \cdot$ Edward W. Szczepaniak $^{1} \cdot$ Lidia S. Szczepaniak $^{1}$ • \\ Kristen L. Knutson ${ }^{2} \cdot$ Stella P. Kim ${ }^{1} \cdot$ Richard N. Bergman ${ }^{1}$
}

Received: 5 July 2015 / Accepted: 14 July 2015 /Published online: 9 August 2015

(C) Springer-Verlag Berlin Heidelberg 2015

\begin{abstract}
Aims/hypothesis A normal consequence of increased energy intake and insulin resistance is compensatory hyperinsulinaemia through increased insulin secretion and/or reduced insulin clearance. Failure of compensatory mechanisms plays a central role in the pathogenesis of type 2 diabetes mellitus; consequently, it is critical to identify in vivo signal(s) involved in hyperinsulinaemic compensation. We have previously reported that high-fat feeding leads to an increase in nocturnal NEFA concentration. We therefore designed this study to test the hypothesis that elevated nocturnal NEFA are an early signal for hyperinsulinaemic compensation for insulin resistance.

Methods Blood sampling was conducted in male dogs to determine $24 \mathrm{~h}$ profiles of NEFA at baseline and during high-fat feeding with and without acute nocturnal NEFA suppression using a partial $\mathrm{A}_{1}$ adenosine receptor agonist.

Results High-fat feeding increased nocturnal NEFA and reduced insulin sensitivity, effects countered by an increase in acute insulin response to glucose $\left(\mathrm{AIR}_{\mathrm{g}}\right)$. Pharmacological NEFA inhibition after 8 weeks of high-fat feeding lowered NEFA to baseline levels and reduced AIR $_{\mathrm{g}}$ with no effect on insulin sensitivity. A significant relationship emerged between

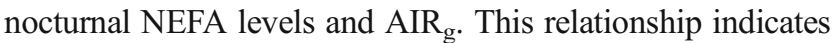

Electronic supplementary material The online version of this article (doi:10.1007/s00125-015-3721-6) contains peer-reviewed but unedited supplementary material, which is available to authorised users.

Josiane L. Broussard

josianebroussard@gmail.com

1 Diabetes and Obesity Research Institute, Cedars-Sinai Medical Center, Los Angeles, 8700 Beverly Blvd, Los Angeles, CA 90048, USA

2 Department of Medicine, University of Chicago, Chicago, IL, USA that the hyperinsulinaemic compensation induced in response to high-fat feeding was prevented when the nocturnal NEFA pattern was returned to baseline.

Conclusions/interpretation Elevated nocturnal NEFA are an important signal for hyperinsulinaemic compensation during diet-induced insulin resistance.

Keywords Disposition index · Glucose tolerance · Insulin compensation $\cdot$ Non-esterified fatty acids $\cdot$ Type 2 diabetes

$\begin{array}{ll}\text { Abbreviations } \\ \text { AIR }_{\mathrm{g}} & \text { Acute insulin response to glucose } \\ \mathrm{DI} & \text { Disposition index } \\ \text { FFAR1 } & \text { Free fatty acid receptor 1 } \\ \mathrm{S}_{\mathrm{I}} & \text { Insulin sensitivity }\end{array}$

\section{Introduction}

In the last decade, the prevalence of type 2 diabetes mellitus has increased by $60 \%$ in the USA [1]. A normal consequence of increased energy intake and insulin resistance is compensatory hyperinsulinaemia through increased insulin secretion and/or reduced insulin clearance. Failure of compensatory mechanisms plays a central role in the pathogenesis of diabetes [2], thus there is a critical need to identify signal(s) involved in hyperinsulinaemic compensation so that successful interventions and treatments can be developed. Although insulin resistance occurs naturally during different stages of a normal life cycle, these transient changes do not result in glucose intolerance in normal individuals. In a healthy individual the appropriate response to insulin resistance is hyperinsulinaemic compensation, resulting in elevated insulin 
levels in the circulation [3-5] due to increased pancreatic beta cell function and/or reduced metabolic clearance of insulin by the liver and other tissues [6].

Understanding the precise mechanisms responsible for compensation is critically important because while glucose intolerance can result from pancreatic islet failure, it could alternatively result from the failure of a signal to initiate the compensatory mechanisms. We have previously concluded that during insulin resistance, glucose - the primary stimulant for beta cell insulin release - is likely not the signal responsible for hyperinsulinaemia [7]. In striking contrast, nocturnal NEFA are markedly elevated after high-fat feeding [7]. A normal nocturnal rise in NEFA has been demonstrated in human volunteers [8], and this nocturnal increase is elevated during sleep-restriction-induced insulin resistance [9]. What is unknown is whether the nocturnal increase in NEFA that occurs in an insulin-resistant state is an initial signal for hyperinsulinaemic compensation in the face of insulin resistance.

The concept of NEFA stimulating insulin secretion is not novel. In recent studies, drug-induced lipolysis has been shown to stimulate insulin secretion [10], and, indeed, intralipid infusion increases insulin secretion in rats [11]. However, studies of infusion and/or experimental upregulation of NEFA release typically reach supraphysiological levels and do not answer questions about the physiological role of circulating NEFA to stimulate insulin secretion during the early stages of metabolic dysfunction.

We therefore tested the hypothesis that elevated nocturnal NEFA are a signal for hyperinsulinaemic compensation during the early development of diet-induced insulin resistance.

\section{Methods}

Animals Male mongrel dogs (Antech, Barnhart, MO, USA; $n=16,>1$ year old, $30.0 \pm 3.5 \mathrm{~kg}$ [mean $\pm \mathrm{SD}])$ were housed in the Cedars-Sinai Medical Center vivarium under controlled kennel conditions (12:12 h light/dark cycle). Animals were accepted into the study following physical examination and a comprehensive blood panel. Dogs were used for experiments only if judged to be in good health as determined by visual inspection, body temperature and haematocrit. The experimental protocol was approved by the Cedars-Sinai Medical Center Institutional Animal Care and Use Committee (IACUC).

Diet Dogs were fed a control weight-maintenance diet comprising one can of Purina Proplan Puppy Chow (10\% protein, $7 \%$ fat, $1.5 \%$ fibre, 76 moisture; Nestle Purina PetCare Company, St Louis, MO, USA) and $825 \mathrm{~g}$ of dry chow (27.7\% protein, $29.9 \%$ fat, $42.4 \%$ carbohydrate, $2.9 \%$ fibre; Lab Diet, Purina Mills, St Louis, MO, USA) for at least 4 weeks before the initiation of the study. The control diet consisted of $14,970 \mathrm{~kJ} /$ day: $39.2 \%$ carbohydrate, $32.5 \%$ fat and $28.3 \%$ protein. During high-fat feeding, the control diet was supplemented with $6 \mathrm{~g} / \mathrm{kg}$ of rendered pork fat (lard) to achieve a $52 \%$ fat diet consisting of $21,025 \mathrm{~kJ} /$ day. Meals were presented for $1 \mathrm{~h}$ from 9:00 hours to 10:00 hours, with food weighed before and after presentation.

MRI During weeks 0, 2 and 6, MRI scans were performed to assess total, subcutaneous and intra-abdominal fat mass as previously described [7]. Image analysis was performed using Slice-O-Matic software (4.3 rev 10; Virtual Magic, Montreal, QC, Canada) by a single experienced observer.

Plasma profiling In eight dogs, $24 \mathrm{~h}$ blood sampling was conducted at weeks $0,2,6$ and again at week 8 with acute nocturnal NEFA suppression. Catheters attached to vascular access ports (Instech Solomon; Plymouth Meeting, PA, USA) were implanted and maintained as previously described [7]. At 6:00 hours on the day of each experiment, animals were brought to the laboratory for hourly blood sampling from 7:00 hours until 8:00 hours on the following morning, at which time an IVGTT was performed.

Suppression of nocturnal NEFA Overnight suppression of NEFA after high-fat feeding was achieved by intravenous injections of a selective partial agonist of the $A_{1}$ adenosine receptor (GS-9667, provided by Gilead Sciences) beginning at 18:00 hours and continuing every $2 \mathrm{~h}$ until 8:00 hours. A dose of $10 \mathrm{mg} / \mathrm{kg}$ every $2 \mathrm{~h}$ was determined to provide maximal inhibition of NEFA. This dose is comparable with that used in clinical studies of NEFA lowering [12].

Frequently sampled IVGTT An IVGTT was performed at weeks $0,2,6$ and 8 . In the subset of eight dogs undergoing $24 \mathrm{~h}$ sampling, IVGTTs were performed immediately following each $24 \mathrm{~h}$ sampling period to test the acute effects of nocturnal NEFA and NEFA lowering on insulin sensitivity and the acute insulin response to glucose. Animals were mildly restrained in a Pavlov sling for this procedure [7]. An intracatheter was inserted into the saphenous or cephalic vein. Blood samples were drawn every $5 \mathrm{~min}$ for $15 \mathrm{~min}$ (three baseline samples), at which time glucose was given as an intravenous bolus $(0.3 \mathrm{~g} / \mathrm{kg}$ body weight $)$. Blood samples were collected at $2,3,4,5,6,8,10,12,14,16,19,22,23$, $24,25,30,40,50,60,70,90,100,120,140,160$ and $180 \mathrm{~min}$. At the $20 \mathrm{~min}$ time point, intravenous insulin $(0.02 \mathrm{U} / \mathrm{kg}$ body weight) was administered.

Sample collection and storage All samples were collected on ice and centrifuged. Plasma was separated and immediately transferred to storage tubes and placed on ice for the remainder of the experiment. On completion of the experiment, 
samples were transferred to $-80^{\circ} \mathrm{C}$ freezers for storage until further analysis. Samples for assay of glucose, insulin, cortisol and catecholamines were collected in tubes pre-coated with lithium fluoride and heparin (Brinkmann Instruments, Westbury, NY, USA). Samples for NEFA were collected in non-heparin tubes containing $50 \mu$ EDTA and coated with paraoxon to inhibit lipase activity. Tubes for insulin, glucose and catecholamines also contained $50 \mu$ EDTA. Tubes for catecholamines contained an additional $25 \mu$ lof ethylene glycol tetraacetic acid (EGTA).

Assays Glucose was measured by a YSI 2300 or 2700 autoanalyser (Yellow Springs Instruments, Yellow Springs, $\mathrm{OH}, \mathrm{USA}$ ). NEFA was measured using a colorimetric method (Wako Pure Chemical Industries, Richmond, VA, USA). Insulin was measured with an ELISA originally developed for human serum or plasma (Linco Research, St Charles, MO, USA) and adapted for dog plasma. The method is based on two murine monoclonal antibodies that bind to different epitopes of insulin but do not bind proinsulin [13]. Cortisol and catecholamines were measured using commercially available kits (cortisol RIA kit from Diagnostic Products, Los Angeles, CA, USA; catecholamines ELISA from Rocky Mountain Diagnostics, Colorado Springs, CO, USA).

Calculations For $24 \mathrm{~h}$ hormone levels, the meal was served after the 9:00 hour blood sample, thus the $8 \mathrm{~h}$ period following meal presentation (10:00-18:00 hours) was considered the postprandial daytime phase. The nocturnal phase was calculated as the AUC from 18:00 hours until the completion of the study the following morning, as previously described [7].

For minimal-model variables, insulin sensitivity $\left(\mathrm{S}_{\mathrm{I}}\right)$, acute insulin response to glucose $\left(\mathrm{AIR}_{\mathrm{g}}\right)$ and disposition index (DI) were calculated using the minimal model of glucose kinetics from the IVGTT (MINMOD 6.02, MinMod, Los Angeles, CA, USA). Glucose tolerance was calculated as the slope of the linear regression of the natural log of plasma glucose concentration from 5 to $19 \mathrm{~min}$.

Statistical analyses Results are presented as means \pm SEM. A linear mixed model was conducted to test the effects of highfat feeding on IVGTT variables and hormonal profiles using a compound symmetry covariance matrix. Time (week $0,2,6$ and 8) was specified as a fixed and repeated factor. A mixedmodel regression analysis was performed to examine the relationship between NEFA and insulin secretion. Individual values that were greater or less than twice the SD were considered statistical outliers and were excluded from the analyses. Statistical analyses were conducted using SPSS (IBM SPSS Statistics for Windows, version 21.0, Armonk, NY, USA). All differences were considered statistically significant when $p<0.05$.

\section{Results}

Increased body weight and body fat on a high-fat diet High-fat feeding resulted in a significant increase in body weight during the course of the study (week $029.9 \pm 1.0 \mathrm{~kg}$, week $231.1 \pm 1.0 \mathrm{~kg}$, week $631.5 \pm 1.1 \mathrm{~kg}$, week $831.6 \pm$ $1.2 \mathrm{~kg} ; p<0.001$ for condition; post hoc testing revealed a significant increase in weight at weeks 2,6 and $8 ; p<0.01$ vs week 0 ). This weight gain was in part due to significant increases in both visceral and subcutaneous fat, as measured by MRI (visceral fat: week $0103 \pm 11 \mathrm{~cm}^{3}$, week $2141 \pm 20 \mathrm{~cm}^{3}$, week $6149 \pm 15 \mathrm{~cm}^{3}$. Subcutaneous fat: week $090 \pm 10$, week $2104 \pm 16$, week $6115 \pm 13 \mathrm{~cm}^{3}$. For both fat depots, there was a significant effect of condition $(p<0.001)$; post hoc testing revealed a significant difference between week 0,2 and 6 for both fat depots; $p<0.01$ ).

Nocturnal NEFA are elevated after high-fat feeding The $24 \mathrm{~h}$ profile of NEFA is shown in Fig. 1a. In all conditions, the meal at 09:00 hours resulted in an immediate inhibition of NEFA, followed by a NEFA increase throughout the day and into the night. High-fat feeding was associated with a significant increase in the nocturnal AUC of NEFA from 18:00 hours (lights off), until 8:00 hours when the $24 \mathrm{~h}$ sampling period concluded ( $p<0.05$; Fig. 1d).

Suppression of NEFA in vivo after high-fat feeding Following 8 weeks of high-fat feeding, we used the partial $\mathrm{A}_{1}$ adenosine receptor agonist GS-9667 (provided by Gilead Sciences) [12] to counter the nocturnal increase in NEFA and to simulate the NEFA pattern observed under baseline feeding conditions. This attempt was successful in that the administration of GS9667 led to a $24 \mathrm{~h}$ pattern that was virtually identical to that observed at week $0(p=1.0)$, despite the continuation of highfat feeding (Fig. 1a).

Nocturnal glycerol was slightly increased after high-fat feeding (Fig. 1b), and the nocturnal AUC of glycerol displayed a similar overall pattern to that of NEFA (Fig. 1e). During suppression of NEFA, the nocturnal AUC of glycerol was significantly reduced. No changes were observed in the triacylglycerol profile after high-fat feeding or with nocturnal NEFA suppression (Fig. 1c).

Glucose and insulin $24 \mathrm{~h}$ profiles after high-fat feeding and NEFA suppression As NEFA are a known potent stimulator of insulin secretion [14], we examined the $24 \mathrm{~h}$ profiles of glucose and insulin at baseline and during high-fat feeding with and without nocturnal NEFA suppression. Average $24 \mathrm{~h}$ levels of fasting and nocturnal glucose were unchanged (Fig. 2a) and nocturnal AUC of insulin displayed a non-significant increase at 6 weeks of high-fat feeding ( $p=0.12$; Fig. $2 b$ ). There were no differences in the glucose or insulin responses to the meal across conditions nor were any changes associated with NEFA 
Fig. 1 The $24 \mathrm{~h}$ profiles of (a) NEFA, (b) glycerol and (c) triacylglycerol at week 0 (black solid line), week 2 (black dashed line), week 6 (red solid line) and week 8 (grey solid line). Nocturnal AUC of (d) NEFA and (e) glycerol. Error bars are SEM; $n=8$. The large black arrow represents an identical meal served at 9:00 hours. Small black arrows indicate nocturnal injections of GS-9667 during week $8 .{ }^{*} p<0.05$. NEFAinhib, NEFA inhibition; W, week

suppression, suggesting that the GS-9667 drug itself did not have any direct effects on fasting insulin levels.

Glucose homeostasis after high-fat feeding and NEFA suppression $S_{I}$ was significantly reduced during high-fat feeding, which became significant after only 2 weeks on a high-fat diet $(p<0.01$; Fig. 3a). This decrease was maintained through week 6 of the study (week $04.5 \pm 0.5$; week $23.6 \pm$ 0.3 ; week $\left.63.6 \pm 0.4[\mathrm{mU} / 1]^{-1} \mathrm{~min}^{-1}\right)$. The acute reduction of nocturnal NEFA at week 8 did not have any significant effect on insulin sensitivity (week $63.6 \pm 0.4$ vs week $82.6 \pm 0.4$ $[\mathrm{mU} / \mathrm{l}]^{-1} \min ^{-1} ; p=1.0$; Fig. 3a).

In response to insulin resistance, $\mathrm{AIR}_{\mathrm{g}}$ exhibited a nonsignificant increase at week 2 , which was maintained until week 6 of high-fat feeding (week $0498 \pm 38$; week $2539 \pm$ 57; week $6562 \pm 52 \mathrm{mU} / 1 \times \mathrm{min}$; Fig. $3 b)$. Following the suppression of nocturnal NEFA at week 8, AIR $_{\mathrm{g}}$ returned to baseline levels (week $0498 \pm 38$ vs week $8393 \pm$ $31 \mathrm{mU} / 1 \times \min$ ).

The product of $\mathrm{S}_{\mathrm{I}}$ and $\mathrm{AIR}_{\mathrm{g}}$, called the DI, refers to beta cell function over time [15]. A reduction in DI indicates an inability of the beta cell to respond to existing insulin resistance and represents an increased risk for the future development of diabetes. There was a significant effect of condition on DI $(p<0.05)$. However, post hoc analyses revealed that the NEFA suppression was the only condition during which there was a reduction in DI from week $0(p<0.05)$ (Fig. 3d). As the DI was maintained during high-fat feeding, we can suppose that although the $\mathrm{AIR}_{\mathrm{g}}$ was not significantly increased during highfat feeding, it was sufficiently increased to maintain the DI and compensate for the reduced insulin sensitivity.

Because AIR $_{\mathrm{g}}$ was reduced by NEFA suppression with no further reduction in $\mathrm{S}_{\mathrm{I}}$, we examined the impact of nocturnal NEFA suppression on glucose tolerance. Glucose tolerance is defined as the rate of disappearance of glucose after a glucose bolus, therefore a reduction in $\mathrm{AIR}_{\mathrm{g}}$ without changes in insulin sensitivity would likely result in reduced glucose tolerance. Indeed, there was an effect of condition and a significant reduction in glucose tolerance was present after NEFA suppression compared with 6 weeks of high-fat feeding (week $62.6 \pm$ 0.2 vs week $81.8 \pm 0.1 \mathrm{mmol} \mathrm{l}^{-1} \mathrm{~min}^{-1} ; p<0.001$; Fig. $3 \mathrm{c}$ ). However, glucose tolerance during high-fat feeding was not significantly different from week 0 (week $02.8 \pm 0.2$ vs week 2 $2.6 \pm 0.2, \mathrm{mmol} \mathrm{l}^{-1} \mathrm{~min}^{-1} ; p=0.13$; week 0 vs week 6 ; $p=$ 0.51 ), suggesting preserved glucose homeostasis during
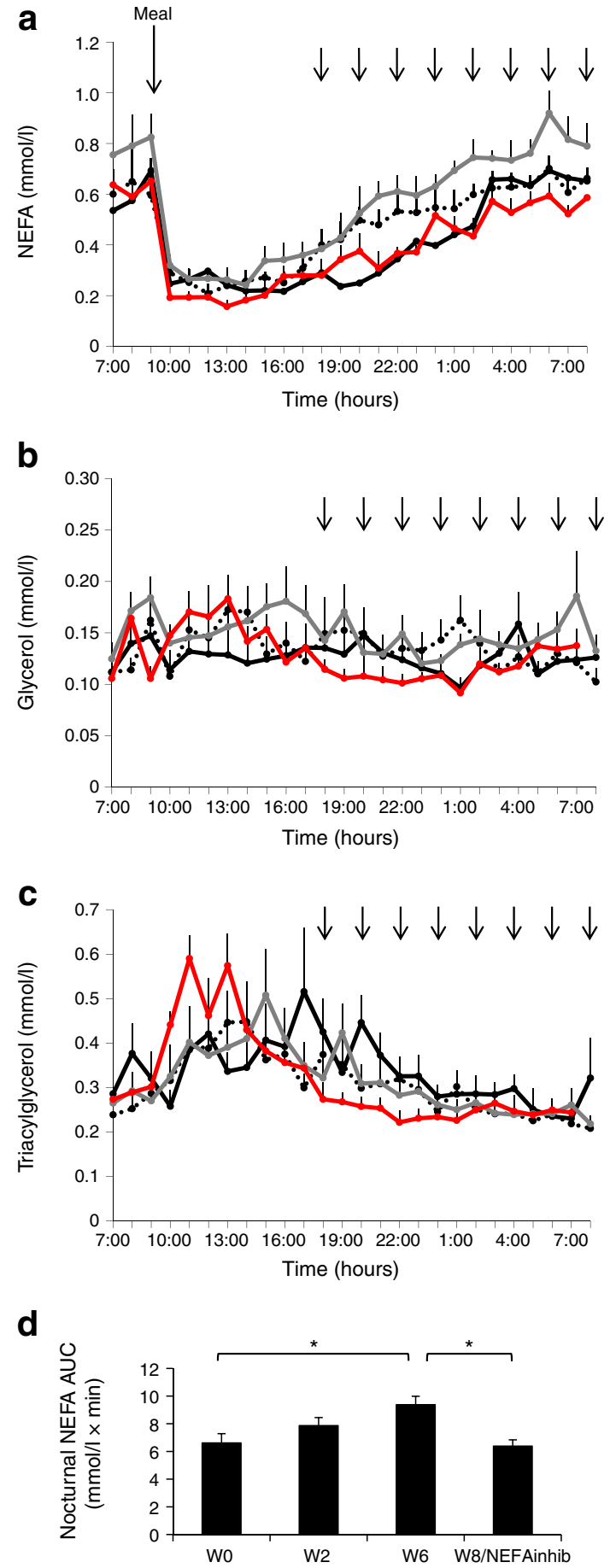

e

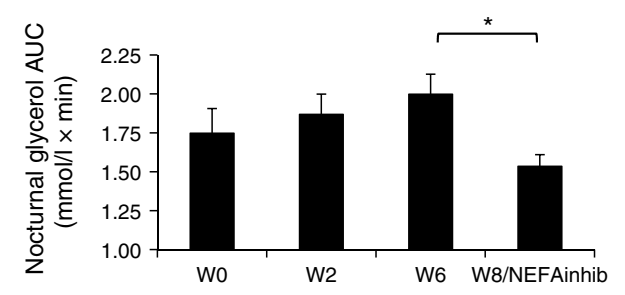

high-fat feeding-induced insulin resistance when nocturnal NEFA were permitted to rise. 
a

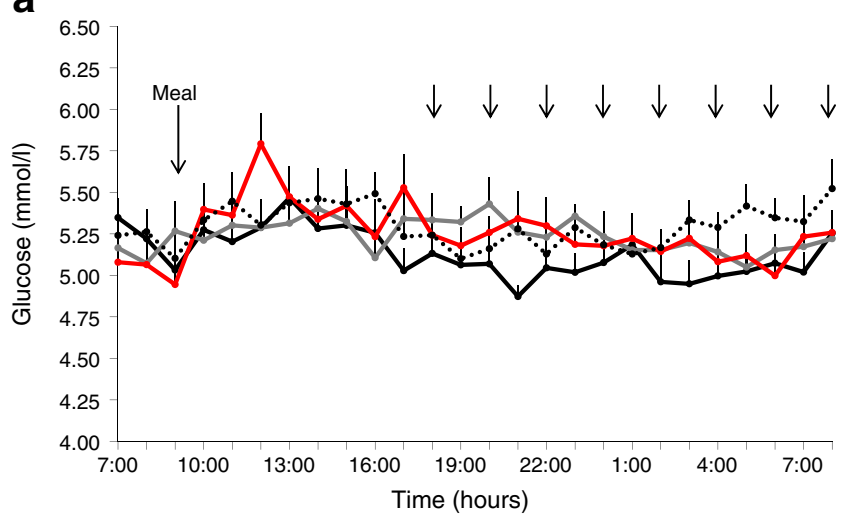

b

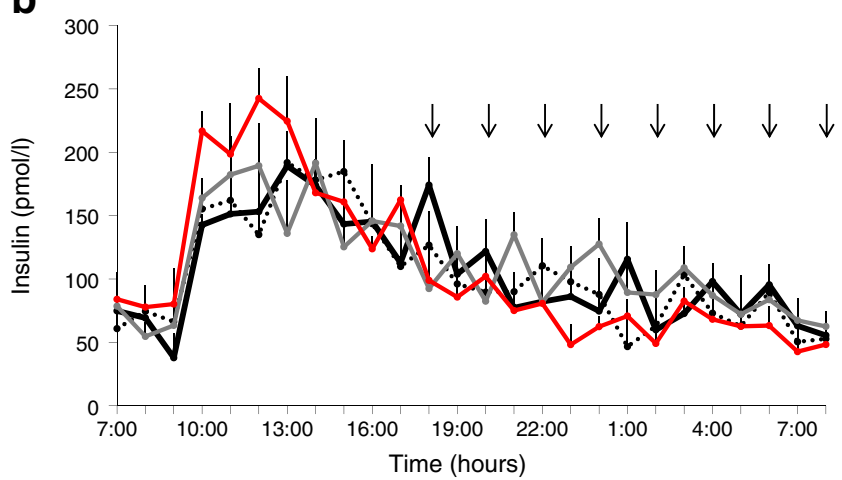

Fig. 2 The 24 h profiles of (a) glucose and (b) insulin at week 0 (black solid line), week 2 (black dashed line), week 6 (red solid line) and week 8 (grey solid line). Error bars are SEM; $n=8$. The large black arrow represents an identical meal served at 9:00 hours. Small black arrows indicate nocturnal injections of GS-9667 during week 8

To confirm that GS-9667 did not have any direct effects on glucose homeostasis we conducted additional experiments in a subset of animals at baseline (control diet only). We conducted IVGTTs before and after repeated drug administration and found no effects of drug treatment on $\mathrm{S}_{\mathrm{I}}$ or $\mathrm{AIR}_{\mathrm{g}}$ when high-fat feeding was not present (electronic supplementary material [ESM] Fig. 1). We also saw no changes in catecholamines or cortisol that could account for changes in glucose homeostasis observed during high-fat feeding (ESM Fig. 2).

A linear relationship exists between nocturnal NEFA and acute insulin compensation We examined the relationship between nocturnal NEFA and insulin secretion in response to a glucose challenge using a mixed-model regression analysis. A significant relationship between nocturnal NEFA and $\mathrm{AIR}_{\mathrm{g}}$ emerged, indicating that, on average, for every unit increase in AUC of nocturnal NEFA, $\mathrm{AIR}_{\mathrm{g}}$ is predicted to increase by $37.9 \mathrm{mU} / 1 \times \min (p<0.01$; Fig. 4$)$.

\section{Discussion}

Insulin resistance is typically accompanied by a compensatory increase in plasma insulin concentration, ensuring that metabolic tissues can utilise glucose. However, some individuals can no longer compensate by increasing insulin and develop type 2 diabetes. Although this failure to compensate is a critical turning point in the progression of diabetes, the loss of the initial signal to increase insulin has already occurred by this time. Here, we show that inhibition of the normal increase in nocturnal NEFA during the early induction of insulin resistance suppresses compensatory hyperinsulinaemia, thus the nocturnal elevation in NEFA may in fact be a signal to stimulate compensatory insulin release. As the failure of such compensatory mechanisms plays a central role in pathogenesis of type 2 diabetes, it is critical to target these as yet unknown signal(s) in the treatment and prevention of diabetes.
Fig. 3 Results from minimalmodel analysis of IVGTTs showing (a) $\mathrm{S}_{\mathrm{I}}$, (b) AIR $_{\mathrm{g}}$, (c) glucose tolerance and (d) DI at week $0(n=16)$, week $2(n=16)$, week $6(n=16)$, week

8/NEFAinhib $(n=8)$. To convert $\mathrm{S}_{\mathrm{I}}$ values to SI units, multiply by 0.167 . DI is calculated as $S_{I}$ $\left([\mathrm{mU} / 1]^{-1} \mathrm{~min}^{-1}\right)$ multiplied by $\operatorname{AIR}_{\mathrm{g}}(\mathrm{mU} / \mathrm{l} \times \mathrm{min})$. To convert $\mathrm{AIR}_{\mathrm{g}}$ and $\mathrm{D}_{\mathrm{I}}$ to SI units, multiply by 6 . $* p<0.05$. NEFAinhib, NEFA inhibition; W, week
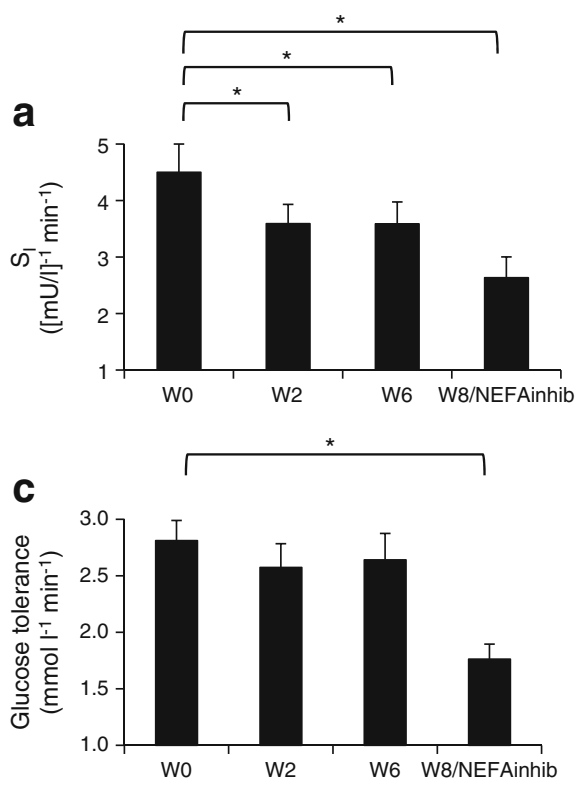
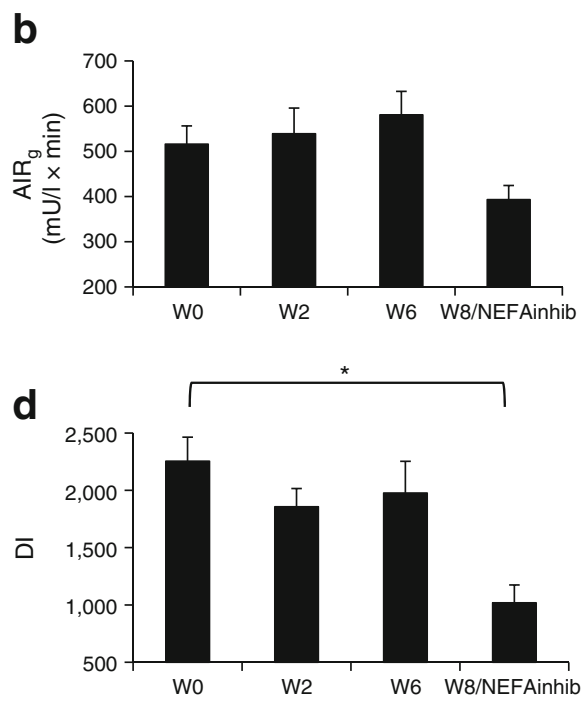


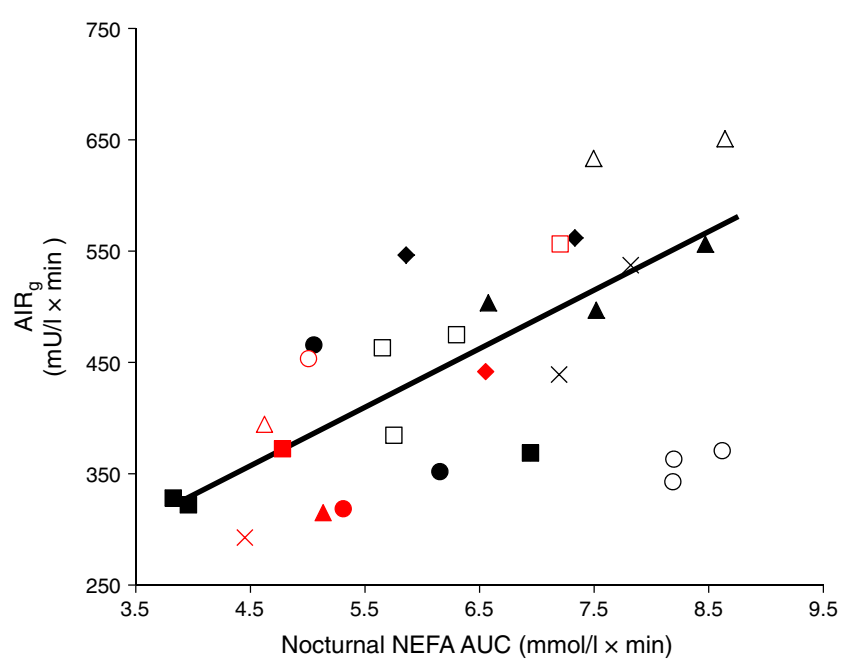

Fig. 4 Correlation between the nocturnal AUC of NEFA and $\mathrm{AIR}_{\mathrm{g}} ; n=8$. Individual animals are represented by the same geometrical shapes; red shapes indicate week 8 when animals received nocturnal injections of GS-9667; $p<0.01$

Previous work from our laboratory has examined a number of compounds in the search for the signal for hyperinsulinaemia and have observed a unique increase in nocturnal NEFA [7]. We therefore proposed to understand the role of nocturnal NEFA in the regulation of compensatory hyperinsulinaemia by inhibiting the nocturnal NEFA increase during high-fat feeding.

On a high-fat diet, animals gained a significant amount of weight, developed insulin resistance and successfully compensated with an increased insulin response. That the insulin response was appropriate was evidenced by an unchanged DI after 6 weeks of high-fat feeding. This upregulation of insulin in response to a glucose challenge represents a physiological coping mechanism for the insulin resistance induced by highfat feeding and is consistent with previous studies showing the time course of compensation to insulin resistance [6].

Unlike our previous study [7], we did not see an effect of high-fat feeding on daytime or meal-related insulin secretion, possibly owing, in part, to differences between fat deposition between these animals. Given the existing correlation between body fat and fasting insulin [16], this may explain our lack of impaired fasting insulin compared with previous studies in which increases in body fat were higher than those observed here [7].

After 8 weeks of high-fat feeding, the increase in nocturnal NEFA was successfully lowered to baseline levels using a partial $\mathrm{A}_{1}$ adenosine receptor agonist. In support of our hypothesis, the compensatory increase in $\mathrm{AIR}_{\mathrm{g}}$ was lost and insulin response returned to baseline levels in the face of nocturnal NEFA suppression after high-fat feeding. Previous studies from our group have examined this high-fat fed canine model at 8,10 and 12 weeks; insulin compensation was present at all time points and no animal decompensated [6]. Therefore, the reduction in $\mathrm{AIR}_{\mathrm{g}}$ following NEFA suppression is unlikely to occur because of beta cell failure, but instead occurs as a direct result of the suppression of nocturnal NEFA.

In a subset of animals during control feeding, we have also determined that no direct effects of administration of the pharmacologic compound exist on glucose or insulin. In addition, while nicotinic acid and its longer-acting analogue acipimox have been shown to alter cardiac function [17, 18], studies using GS-9667 have shown that it can inhibit lipolysis without any unwanted cardiac side effects $[12,19,20]$. Thus, our findings are not likely to be explained by any haemodynamic changes due to drug administration.

If suppression of nocturnal NEFA leads to a reduction in insulin secretion, glucose tolerance would be expected to be impaired. Indeed, there was a trend for reduced glucose tolerance after 2 weeks of high-fat feeding - at the time when NEFA are beginning to rise, but are not yet significantly elevated. By 6 weeks, NEFA were elevated and glucose tolerance returned to baseline levels, suggesting adequate insulin compensation. However, when nocturnal NEFA were suppressed at week 8 , glucose tolerance was impaired, supporting our hypothesis that without an increase in nocturnal NEFA there will be uncompensated insulin resistance, in conjunction with impaired glucose tolerance.

Previous studies have shown an improvement in glucose metabolism and insulin sensitivity with NEFA suppression using acipimox [18, 21-25]. The mechanisms by which acipimox can improve $S_{I}$ have been suggested to be reduced skeletal muscle inflammation [26] and improved mitochondrial function [24]. However, we did not observe any improvement in $\mathrm{S}_{\mathrm{I}}$ after NEFA suppression, nor did we see a relationship between nocturnal NEFA and $\mathrm{S}_{\mathrm{I}}$, possibly because of differences in drug choices.

The selective partial agonist of the $\mathrm{A}_{1}$ adenosine receptor, GS-9667, was chosen because it is not associated with desensitisation, or tachyphylaxis, after repeated treatments [19]. Neither is it followed by a rebound increase in NEFA as seen with the long-term use of nicotinic acid or acipimox [27-31], which has been suggested to lead to insulin resistance $[32,33]$. Notably, the rebound increase in NEFA during nicotinic acid infusion is likely due to an increase in basal lipolysis [31]. Most importantly, however, is evidence that acipimox may have direct effects on muscle mitochondria in humans [34], suggesting that its effects on $\mathrm{S}_{\mathrm{I}}$ may not be solely mediated by a reduction in NEFA; therefore we cannot compare the effects with those of the drug used in the current study.

While GS-9667 has been shown to improve insulin sensitivity [35] and glucose uptake [36], these studies have thus far been conducted only in rodents; no clinical or large animal studies have yet reported an improvement in $\mathrm{S}_{\mathrm{I}}$ following NEFA suppression using GS-9667. The first two clinical studies have focused on pharmacokinetics and shown reproducible reductions in NEFA without desensitisation, rebound or cardiac impairments [12], but these did not report any $\mathrm{S}_{\mathrm{I}}$ measurements. 
A large potential difference between our model and studies of rodents is the marked difference in the degree of weight gain during high-fat feeding. Depending on starting weight, rodents in the GS-9667 studies gained up to $45 \%$ of baseline body mass before NEFA suppression was conducted [35]. The weight gain we typically see in our canine model, as well as in human weight gain, is drastically different at $5-7 \%$ and this may explain discrepant results for change in $\mathrm{S}_{\mathrm{I}}$ following NEFA reduction using GS-9667.

Finally, a significant positive correlation was observed between nocturnal NEFA and morning insulin response to glucose, supporting the concept that nocturnal plasma NEFA are particularly important for beta cell compensation during highfat feeding. This relationship exists only with the nocturnal NEFA AUC and not fasting NEFA.

It is import to note that as these animals are only mildly overweight, they do not yet display fasting hyperinsulinaemia. Therefore, the elevated nocturnal NEFA are likely an early signal for beta cell compensation. In later stages of obesity it is probable that many factors are important in sustaining beta cell function. During obesity, excessive NEFA may be a major cause of beta cell dysfunction [37-41].

NEFA can act as ligands for multiple G-protein-coupled receptors on other tissues, as reviewed by Talukdar and colleagues [42]. Specifically, GPR120 is the physiological receptor for omega-3 NEFAs in macrophages and adipocytes and may mediate inflammation, raising the possibility that targeting lipid-sensing receptors may have many therapeutic benefits in a number of different tissues and disease states [42].

This is particularly relevant to the ongoing research on pancreas-specific NEFA receptors. FFAR1s (free fatty acid receptor 1, also known as G-protein-coupled receptor 40 or GPR40) are predominantly expressed in beta cells and stimulate insulin secretion when activated by long-chain fatty acids [43]. Studies in rodents have shown that overexpression of GPR40 improves glucose tolerance in mice [44] and that deletion of the receptor impairs glucose-stimulated insulin secretion in vivo [45]. Recent clinical evidence supports the role of FFAR1 agonists as pharmaceutical targets to stimulate or enhance insulin secretion [46]. In a 12 week phase II clinical trial, the GPR40 agonist TAK-875 was shown to stimulate insulin secretion and improve glucose homeostasis in type 2 diabetic patients [47].

Given the clinical effects of GPR 40 agonists on insulin secretion in diabetic patients, we believe that the present data indicate that nocturnal NEFA may be important in the context of early-onset insulin resistance and a critical physiological signal for beta cell compensation. If elevated nocturnal NEFA are a signal for hyperinsulinaemic compensation, the cause of eventual beta cell failure may lie in the signal itself, or lack thereof. Therefore, pancreas-specific NEFA analogues given nocturnally may represent a treatment option for early diabetic patients and/or patients with impaired glucose tolerance who still possess the ability to increase insulin secretion, yet for unknown reasons are unable to compensate for insulin resistance.

Acknowledgements The authors thank R. Thomas, Biomedical Sciences Department, Cedars-Sinai Medical Center, Los Angeles, CA, USA, for performing the insulin, cortisol and catecholamine assays and E. Paredes and the Comparative Medicine staff, Cedars-Sinai Medical Center, for their assistance with and care for our animals.

Some of the data were presented as a poster abstract at the American Diabetes Association meeting in 2013.

Funding This work was supported by NIH grants DK29867 and DK27619 to RNB and Society in Science, the Branco Weiss Fellowship, administered by the ETH Zürich (to JLB).

Duality of interest The authors declare that there is no duality of interest associated with this manuscript.

Contribution statement JLB and RNB designed the study, researched data, analysed data and wrote the manuscript. CMK and SPK contributed to study design, researched data, contributed to discussions, and reviewed and edited the manuscript. AVBC, IAB, RLP and EWS researched data, and reviewed and edited the manuscript. LSS and KLK researched data, analysed data, and reviewed and edited the manuscript. All authors approved the final version of the manuscript. RNB is the guarantor of this work.

\section{References}

1. Cowie CC, Rust KF, Byrd-Holt DD et al (2006) Prevalence of diabetes and impaired fasting glucose in adults in the U.S. population: National Health And Nutrition Examination Survey 19992002. Diabetes Care 29:1263-1268

2. Prentki M, Nolan CJ (2006) Islet beta cell failure in type 2 diabetes. J Clin Invest 116:1802-1812

3. Kahn SE, Beard JC, Schwartz MW et al (1989) Increased beta-cell secretory capacity as mechanism for islet adaptation to nicotinic acid-induced insulin resistance. Diabetes 38:562-568

4. Weyer C, Bogardus C, Mott DM, Pratley RE (1999) The natural history of insulin secretory dysfunction and insulin resistance in the pathogenesis of type 2 diabetes mellitus. J Clin Invest 104:787-794

5. Cerutti F, Sacchetti C, Bessone A, Rabbone I, Cavallo-Perin P, Pacini G (1998) Insulin secretion and hepatic insulin clearance as determinants of hyperinsulinaemia in normotolerant grossly obese adolescents. Acta Paediatr 87:1045-1050

6. Mittelman SD, van Citters GW, Kim SP et al (2000) Longitudinal compensation for fat-induced insulin resistance includes reduced insulin clearance and enhanced beta-cell response. Diabetes 49: 2116-2125

7. Kim SP, Catalano KJ, Hsu IR, Chiu JD, Richey JM, Bergman RN (2007) Nocturnal free fatty acids are uniquely elevated in the longitudinal development of diet-induced insulin resistance and hyperinsulinemia. Am J Physiol Endocrinol Metab 292:E1590-E1598

8. Schlierf G, Dorow E (1973) Diurnal patterns of triglycerides, free fatty acids, blood sugar, and insulin during carbohydrate-induction in man and their modification by nocturnal suppression of lipolysis. $\mathrm{J}$ Clin Invest 52:732-740

9. Broussard JL, Chapotot F, Abraham V et al (2015) Sleep restriction increases free fatty acids in healthy men. Diabetologia 58:791-798

10. MacPherson RE, Castellani L, Beaudoin MS, Wright DC (2014) Evidence for fatty acids mediating CL 316,243-induced reductions in blood glucose in mice. Am J Physiol Endocrinol Metab 307: E563-E570 
11. Lai E, Pettersson U, Verdugo AD et al (2014) Blood lipids affect rat islet blood flow regulation through beta(3)-adrenoceptors. Am J Physiol Endocrinol Metab 307:E653-E663

12. Staehr PM, Dhalla AK, Zack J et al (2013) Reduction of free fatty acids, safety, and pharmacokinetics of oral GS-9667, an A(1) adenosine receptor partial agonist. J Clin Pharmacol 53:385-392

13. Steil GM, Ader M, Moore DM, Rebrin K, Bergman RN (1996) Transendothelial insulin transport is not saturable in vivo. No evidence for a receptor-mediated process. J Clin Invest 97:1497-1503

14. Boden G (2005) Free fatty acids and insulin secretion in humans. Curr Diab Rep 5:167-170

15. Bergman RN (1989) Lilly lecture 1989. Toward physiological understanding of glucose tolerance. Minimal-model approach. Diabetes 38:1512-1527

16. Folsom AR, Jacobs DR Jr, Wagenknecht LE et al (1996) Increase in fasting insulin and glucose over seven years with increasing weight and inactivity of young adults. The CARDIA Study. Coronary Artery Risk Development in Young Adults. Am J Epidemiol 144: 235-246

17. Tuunanen H, Engblom E, Naum A et al (2006) Free fatty acid depletion acutely decreases cardiac work and efficiency in cardiomyopathic heart failure. Circulation 114:2130-2137

18. Lehto HR, Parkka J, Borra R et al (2012) Effects of acute and oneweek fatty acid lowering on cardiac function and insulin sensitivity in relation with myocardial and muscle fat and adiponectin levels. J Clin Endocrinol Metab 97:3277-3284

19. Dhalla AK, Santikul M, Smith M, Wong MY, Shryock JC, Belardinelli L (2007) Antilipolytic activity of a novel partial A1 adenosine receptor agonist devoid of cardiovascular effects: comparison with nicotinic acid. J Pharmacol Exp Ther 321:327-333

20. Fatholahi M, Xiang Y, Wu Y et al (2006) A novel partial agonist of the A(1)-adenosine receptor and evidence of receptor homogeneity in adipocytes. J Pharmacol Exp Ther 317:676-684

21. Bajaj M, Suraamornkul S, Kashyap S, Cusi K, Mandarino L, DeFronzo RA (2004) Sustained reduction in plasma free fatty acid concentration improves insulin action without altering plasma adipocytokine levels in subjects with strong family history of type 2 diabetes. J Clin Endocrinol Metab 89:4649-4655

22. Bajaj M, Suraamornkul S, Romanelli A et al (2005) Effect of a sustained reduction in plasma free fatty acid concentration on intramuscular long-chain fatty Acyl-CoAs and insulin action in type 2 diabetic patients. Diabetes 54:3148-3153

23. Rigazio S, Lehto HR, Tuunanen $\mathrm{H}$ et al (2008) The lowering of hepatic fatty acid uptake improves liver function and insulin sensitivity without affecting hepatic fat content in humans. Am J Physiol Endocrinol Metab 295:E413-E419

24. Daniele G, Eldor R, Merovci A et al (2014) Chronic reduction of plasma free fatty acid improves mitochondrial function and wholebody insulin sensitivity in obese and type 2 diabetic individuals. Diabetes 63:2812-2820

25. Santomauro AT, Boden G, Silva ME et al (1999) Overnight lowering of free fatty acids with Acipimox improves insulin resistance and glucose tolerance in obese diabetic and nondiabetic subjects. Diabetes 48:1836-1841

26. Liang H, Tantiwong P, Sriwijitkamol A et al (2013) Effect of a sustained reduction in plasma free fatty acid concentration on insulin signalling and inflammation in skeletal muscle from human subjects. J Physiol 591:2897-2909

27. Kelly JJ, Lawson JA, Campbell LV et al (2000) Effects of nicotinic acid on insulin sensitivity and blood pressure in healthy subjects. $\mathrm{J}$ Hum Hypertens 14:567-572

28. Worm D, Henriksen JE, Vaag A, Thye-Ronn P, Melander A, BeckNielsen H (1994) Pronounced blood glucose-lowering effect of the antilipolytic drug acipimox in noninsulin-dependent diabetes mellitus patients during a 3-day intensified treatment period. J Clin Endocrinol Metab 78:717-721
29. Saloranta C, Taskinen MR, Widen E, Harkonen M, Melander A, Groop L (1993) Metabolic consequences of sustained suppression of free fatty acids by acipimox in patients with NIDDM. Diabetes 42:1559-1566

30. Vaag AA, Beck-Nielsen H (1992) Effects of prolonged Acipimox treatment on glucose and lipid metabolism and on in vivo insulin sensitivity in patients with non-insulin dependent diabetes mellitus. Acta Endocrinol (Copenh) 127:344-350

31. Oh YT, Oh KS, Choi YM et al (2011) Continuous 24-h nicotinic acid infusion in rats causes FFA rebound and insulin resistance by altering gene expression and basal lipolysis in adipose tissue. Am J Physiol Endocrinol Metab 300:E1012-E1021

32. Leung N, Sakaue T, Carpentier A, Uffelman K, Giacca A, Lewis GF (2004) Prolonged increase of plasma non-esterified fatty acids fully abolishes the stimulatory effect of 24 hours of moderate hyperglycaemia on insulin sensitivity and pancreatic beta-cell function in obese men. Diabetologia 47:204-213

33. Poynten AM, Gan SK, Kriketos AD et al (2003) Nicotinic acidinduced insulin resistance is related to increased circulating fatty acids and fat oxidation but not muscle lipid content. Metab Clin Exp 52:699-704

34. van de Weijer T, Phielix E, Bilet L et al (2015) Evidence for a direct effect of the NAD+ precursor acipimox on muscle mitochondrial function in humans. Diabetes 64:1193-1201

35. Dhalla AK, Wong MY, Voshol PJ, Belardinelli L, Reaven GM (2007) A1 adenosine receptor partial agonist lowers plasma FFA and improves insulin resistance induced by high-fat diet in rodents. Am J Physiol Endocrinol Metab 292:E1358-E1363

36. Shearer J, Severson DL, Su L, Belardinelli L, Dhalla AK (2009) Partial A1 adenosine receptor agonist regulates cardiac substrate utilization in insulin-resistant rats in vivo. J Pharmacol Exp Ther 328:306-311

37. DeFronzo RA (2004) Dysfunctional fat cells, lipotoxicity and type 2 diabetes. Int J Clin Pract Suppl: 9-21

38. Boden G (2003) Effects of free fatty acids (FFA) on glucose metabolism: significance for insulin resistance and type 2 diabetes. Exp Clin Endocrinol Diabetes 111:121-124

39. Boden G, Lebed B, Schatz M, Homko C, Lemieux S (2001) Effects of acute changes of plasma free fatty acids on intramyocellular fat content and insulin resistance in healthy subjects. Diabetes 50 : $1612-1617$

40. Roden M, Price TB, Perseghin G et al (1996) Mechanism of free fatty acid-induced insulin resistance in humans. J Clin Invest 97 : 2859-2865

41. Chavez AO, Kamath S, Jani R et al (2010) Effect of short-term free fatty acids elevation on mitochondrial function in skeletal muscle of healthy individuals. J Clin Endocrinol Metab 95:422-429

42. Talukdar S, Olefsky JM, Osborn O (2011) Targeting GPR120 and other fatty acid-sensing GPCRs ameliorates insulin resistance and inflammatory diseases. Trends Pharmacol Sci 32:543-550

43. Kebede M, Alquier T, Latour MG, Semache M, Tremblay C, Poitout V (2008) The fatty acid receptor GPR40 plays a role in insulin secretion in vivo after high-fat feeding. Diabetes 57:2432-2437

44. Nagasumi K, Esaki R, Iwachidow K et al (2009) Overexpression of GPR40 in pancreatic beta-cells augments glucose-stimulated insulin secretion and improves glucose tolerance in normal and diabetic mice. Diabetes 58:1067-1076

45. Alquier T, Peyot ML, Latour MG et al (2009) Deletion of GPR40 impairs glucose-induced insulin secretion in vivo in mice without affecting intracellular fuel metabolism in islets. Diabetes 58:2607-2615

46. Wagner R, Kaiser G, Gerst F et al (2013) Reevaluation of fatty acid receptor 1 as a drug target for the stimulation of insulin secretion in humans. Diabetes 62:2106-2111

47. Burant CF, Viswanathan P, Marcinak J et al (2012) TAK-875 versus placebo or glimepiride in type 2 diabetes mellitus: a phase 2, randomised, double-blind, placebo-controlled trial. Lancet 379: 1403-1411 